\title{
EGF-induced adipose tissue mesothelial cells undergo functional vascular smooth muscle differentiation
}

\author{
CC Lachaud ${ }^{1}$, J López-Beas ${ }^{1}$, B Soria ${ }^{*, 1,2,3}$ and A Hmadcha ${ }^{*, 1,2,3}$
}

Recent studies suggested that the post-natal mesothelium retain differentiative potential of the embryonic mesothelium, which generates fibroblasts and vascular smooth muscle cells (VSMCs), in developing coelomic organs via epithelial-to-mesenchymal transition (EMT). Whether adult mesothelial cells (MCs) are able to give rise to functional VSMCs in vitro and which are the factors and mechanisms directing this process remain largely unknown. Here, we isolated adipose tissue MCs (ATMCs) from adult mice, and demonstrated that ATMCs cultured in a serum-containing media supplemented with epidermal growth factor (EGF) efficiently increased both their proliferation and EMT above levels found in only serum-containing media cultures. EGF-induced ATMCs gained phosphorylation of the EGF receptor and activated simultaneously ILK/Erk1/2, PI3K/Akt and Smad2/3-dependent pathways. Sequential subculture onto collagen-I surface efficiently improved their vasculogenic EMT towards cells featuring VSMCs ( $\alpha$-SMA, calponin, caldesmon, SM22 $\alpha$, desmin, SM-MHC, smoothelin-B and PDGFR- $\beta$ ) that could actively contract in response to receptor and non-receptor-mediated vasoactive agonists. Overall, our results indentify EGF signalling as a robust vasculogenic inductive pathway for ATMCs, leading to their transdifferentiation into functional VSMC-like cells.

Cell Death and Disease (2014) 5, e1304; doi:10.1038/cddis.2014.271; published online 26 June 2014

Stem cell-based pro-angiogenic therapies hold great promise to revascularize ischemic tissues in patients with acute myocardial infarction or chronic limb ischemia. ${ }^{1-4}$ The plasticity of pluripotent embryonic stem cells (ESCs) and induced pluripotent stem (iPS) cells allows their easy derivation towards $|s|-1^{+}$multipotent cardiovascular progenitors that clonally give rise to cardiomyocytes, vascular smooth muscle cells (VSMCs) and endothelial cells, ${ }^{5,6}$ the major cell types of cardiovascular tissues. Safety concerns, differentiation efficiency, overcoming immune rejection and the inherent tumourigenicity of pluripotent stem cells, however, remains a major issue hindering their clinical application ${ }^{7,8}$ and will require the validation of efficient gating strategies allowing the purification of ESC- and iPSderived multipotent cardiovascular progenitors for future use in cardiovascular regenerative medicine.

Adult tissues retain a small subset of resident undifferentiated stem cells that can self-renew asymmetrically to generate committed progenitors for the replenishment of the different cellular phenotypes that are lost during normal tissue turnover. Although adult stem cells display restricted lineage differentiation potential and limited proliferative capacities, their lack of tumourigenicity has attracted great attention for establishing safe cell-based regenerative therapies..$^{9-11}$ Stromal mesenchymal stem cells (MSCs) are multipotent stem cells residing around the vasculature of virtually all organs and vascularized tissues. ${ }^{12,13}$ It is now widely accepted that MSCs display significant immunosuppressive activity ${ }^{14}$ and angiogenic potential and improve long-term neovascularization outcomes of ischemic tissues ${ }^{4}$ mainly through their paracrine secretion of pro-angiogenic factors such as bFGF, EGF, PDGF-BB, VEGF and TGF $\beta 1$, rather by a direct incorporation into the neovasculature as it was initially thought. ${ }^{15}$ Despite the extensive focus on the pro-angiogenic potential of MSCs, the identification of new sources of adult stem cells with neovascularization potential remains a goal that is under research.

The adult mesothelium is a squamous epithelial layer of mesoderm origin lining coelomic cavities and the visceral organs housed within. Cumulating evidence indicates that the adult mesothelium is a rich reservoir of mesothelial cells (MCs) with pro-vasculogenic potential. ${ }^{16-19}$ The adult mesothelium was thought to be a 'quiescent tissue' solely endowed with physiological functions such as to maintain serosal integrity and inflammation and to secrete large amounts of 'lubricants' to favour the correct sliding of opposite serosal layers (i.e., for the beating heart). A recent report, however, set a breakthrough in this concept showing that the post-natal mesothelium remains a source of progenitor cells giving rise to fibroblasts and VSMCs in visceral organs of healthy mice. ${ }^{19}$ Furthermore, it was also shown that MCs give rise to hepatic stellate cells and myofibroblasts in injured liver. ${ }^{20}$ Another striking example recently demonstrates that the mesothelium is a source for adipocytes that often physically attach to the visceral organs. ${ }^{21}$

\footnotetext{
${ }^{1}$ Department of Stem Cells, Andalusian Center for Molecular Biology and Regenerative Medicine, Sevilla, Spain and ${ }^{2}$ CIBER de Diabetes y Enfermedades Metabólicas Asociadas (CIBERDEM), Barcelona, Spain

${ }^{*}$ Corresponding authors: B Soria and A Hmadcha, Department of Stem Cells, Andalusian Center for Molecular Biology and Regenerative Medicine (CABIMER), Avenida Americo Vespucio s/n Parque Científico y Tecnológico Cartuja 93, Sevilla 41092, Spain. Tel: +34 954468004 (BS) or +34 954468373 (AH); Fax: +34 954461664 ; E-mail: bernat.soria@cabimer.es (BS) or karim.hmadcha@cabimer.es (AH)

${ }^{3}$ These authors share the senior authorship.

Abbreviations: VSMCs, vascular smooth muscle cells; EMT, epithelial-to-mesenchymal transition; MCs, mesothelial cells; ATMCs, adipose tissue mesothelial cells; EGF, epidermal growth factor; ESCs, embryonic stem cells; iPS, induced pluripotent stem cells; MSCs, mesenchymal stem cells; UtMCs, uterine mesothelial cells; AT, adipose tissue; BMe, high glucose-based media; qPCR, quantitative real-time PCR; ET1, endothelin-1; SM, smooth muscle; BSA, bovine serum albumin Received 28.3.14; revised 01.5.14; accepted 20.5.14; Edited by Y Shi
} 
The findings that adult MCs of human and rodent origin can recapitulate in vitro an epithelial-to-mesenchymal transition (EMT) and acquire SMCs markers in response to provasculogenic and morphogenic growth factors (i.e, TGF- $\beta 1$, PDGF$\mathrm{BB}, \mathrm{bFGF}$ and EGF) ${ }^{10,16,17,22-24}$ led to the hypothesis that adult MCs may retain the differentiative potential of embryonic MCs, which were shown to generate fibroblasts and VSMCs in the developing heart, lung, gut and liver. ${ }^{25-30}$ We recently pushed onward this concept by demonstrating that adult mouse uterine MCs (UtMCs) subjected to provasculogenic culture undergo EMT towards progenitors that can subsequently acquire properties of differentiated VSMCs upon sequential subculture. ${ }^{18}$ Despite these exiting findings uncovering an unexpected mesodermal plasticity and vasculogenic potential for adult MCs, the factors and mechanisms inducing and directing their vasculogenic differentiation towards a functional VSMCs phenotype remain largely unknown.

The visceral adipose tissue (AT) is composed of several adipose depots, including mesenteric, epididymal white AT and perirenal depots. In humans, the major visceral AT depot corresponds to the greater omentum, a large fold of the peritoneum. $^{31}$ In mice, the major visceral AT depots are attached to the uterus and ovaries in females and the epididyme and testes in males. Its tremendous remodelling capacity allows its rapid adaptation to an excess food intake through adipocyte hyperplasia, a process that is closely coupled with neovascularization. ${ }^{32,33}$

The expansion and neovascularization potential of the visceral AT is likely to indicate that its surrounding mesothelium retain strong vasculogenic potential, a particularity that should make this tissue a valuable source of cells for cardiovascular regenerative therapy.

Herein, we show that a gentle trypsinization of the adult mouse uterine AT can efficiently and reliably detach a highly enriched population of AT mesothelial cells (ATMCs) from its covering mesothelium. ATMCs cultured in a high glucosebased media (BMe) with serum and $50 \mathrm{ng} / \mathrm{ml}$ of epidermal growth factor (EGF; termed BMe $+50 E G F$ ) could actively proliferate and acquire EMT, progenitor and cardiovascular developmental markers. Upon repeated subculture onto collagen type I-coated surface, ATMCs drastically reduced their proliferation rate while improving in turn their transdifferentiation towards fibroblastic cells displaying molecular and functional characteristics of differentiated VSMCs.

\section{Results}

Immunophenotype characterization of trypsin isolated ATMCs. A gentle trypsinization of the adult mouse uterine AT could efficiently disrupt and detach its outermost mesothelium layer typically in the form of small sheets of flattened MCs that rapidly adopted 'grap-like' morphologies once resuspended in serum-containing media (Figure 1a). Flow cytometry and immunofluorescence analysis of trypsin isolated cells could confirm their wide immunoexpression of the epithelial tight junction proteins ZO-1, E-cadherin and $\beta$-catenin and cell adhesion molecules CD29 and CD54 (Figures $1 \mathrm{~b}$ and $\mathrm{c}$ ). Whole-mount immunofluorescence analysis of the uterine AT could confirm the constitutive expression of these markers in its outermost mesothelium layer (Supplementary Figure 1). Freshly trypsin isolated cells, however, contained a significant subset of cells expressing the pan-haematopoietic marker CD45 $(23.86 \pm 7.96 \%)$ and in much less extent of cells expressing the monocyte and macrophage marker CD11b $(5.16 \pm 5.33 \%)$, suggesting phenotypic heterogeneity within the $\mathrm{CD} 45^{+}$subset. Whole-mount immunofluorescence analysis of the uterine AT mesothelium further indicated that it contains a significant population of $\mathrm{CD}_{4} 5^{+}$cells, and hence explain why $\mathrm{CD}_{4} 5^{+}$cells were detached during trypsinization together with ATMCs (Supplementary Figure 1). Trypsin isolated cells heterogeneously expressed Sca1 (50.9 $\pm 17.9 \%)$ and CD90.2 (37.4 $\pm 28.3 \%)$, two markers that were accordingly found to be expressed heterogeneously in the AT mesothelium (Supplementary Figure 1). The lack of expression of endothelial markers expression (CD31 and CD106) among trypsin isolated cells strongly suggests that our trypsinization procedure was not disrupting and detaching the submesothelial microvasculature to any significant extent. Consistent with their mesothelial nature, trypsin isolated cells cultured for 5 days in BMe (media lacking EGF) could establish a cobblestone monolayer of cells that widely immunoexpressed the mesothelial markers WT1, CD54, ZO-1 and $\beta$-catenin (Figure 1d).

Early EGF-induced ATMCs undergo EMT and acquire vascular smooth muscle (SM) markers expression. During the 15 days of our differentiation protocol (Figure 2a), ATMCs that were cultured in BMe $+50 E G F$ rapidly initiated proliferation and also morphological changes consistent with EMT. The subset of the early EGF-induced ATMCs, which was actively proliferating mainly, corresponded to small polygonal to rounded refringent cells (Figure $2 b$ ), a subset of ATMCs that was found to strongly express the nuclear Ki-67 proliferation antigen (Supplementary Figure 2).

Other subset of the early EGF-induced ATMCs rather displayed transitional epitheloid-fibroblastoid morphologies, which are consistent with EMT. Their ongoing EMT was also confirmed by immunofluorescence analysis on the basis of their gain of expression of $\alpha$-SMA and Smtn-B after only 3 days in culture (Figure $2 b$ and Table 1). Immunofluorescence analysis of the early EGF-induced ATMCs revealed their increased expression of Gata-4, gain of expression of the progenitor cells marker nestin and also in distinct degrees of $\alpha$-SMA, SM22 $\alpha$, calponin, caldesmon, desmin, SMM, SM-MHC, Smtn-B and PDGFR- $\beta$ markers, indicating hence that they had already initiated a vasculogenic EMT (Supplementary Figure 3 and Table 1).

We used quantitative real-time PCR (qPCR) analysis to quantify the change in expression of EMT, SM and cardiac genes suffered by the EGF-induced ATMCs through their culture period. Consistent with their initiation of EMT, the early EGF-induced ATMCs displayed a strong up-expression of snail, a master gene upregulated during EMT (Figure 3a). In less extent, they also displayed a significant increase in their expression of other EMT genes such as twist and slug (Figure 3a). Accordingly, the epithelial genes, E-cadherin and CK18, were in turn strongly downregulated. In less extent, WT1 expression was also slightly decreased through their time culture period. 
a

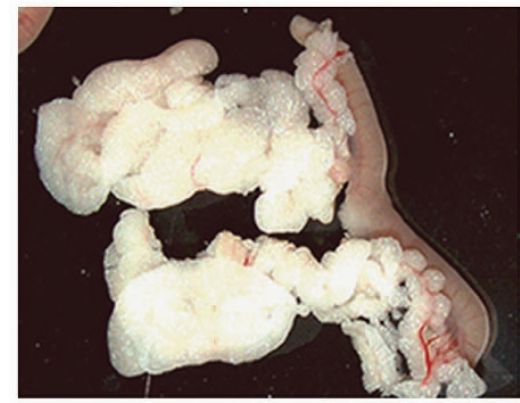

Uterine Adipose Tissue (AT)

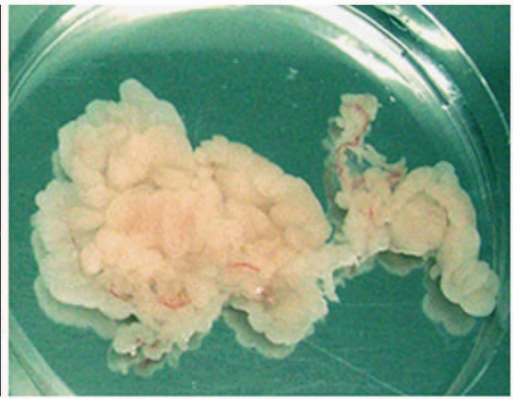

AT trypsin isolated cells

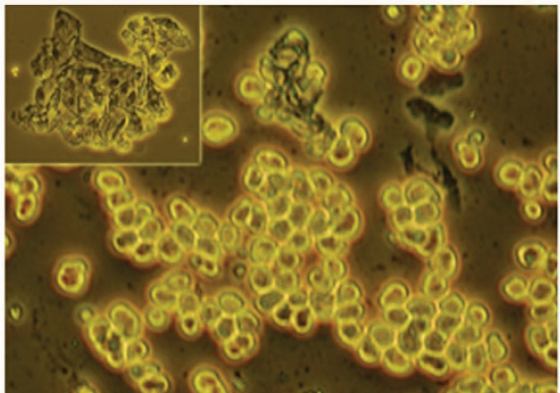

b
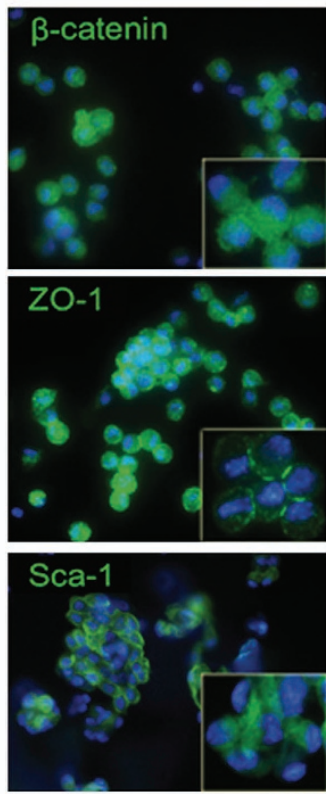
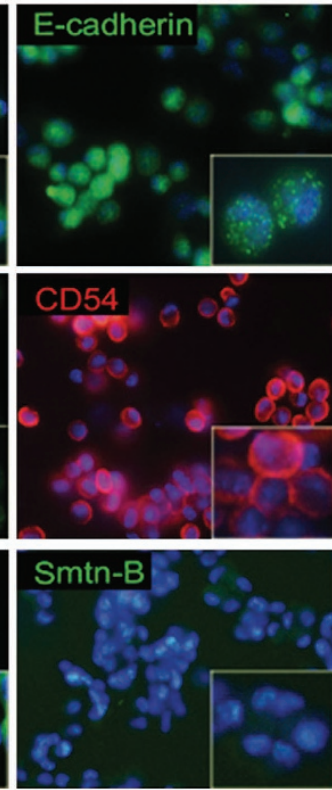

c

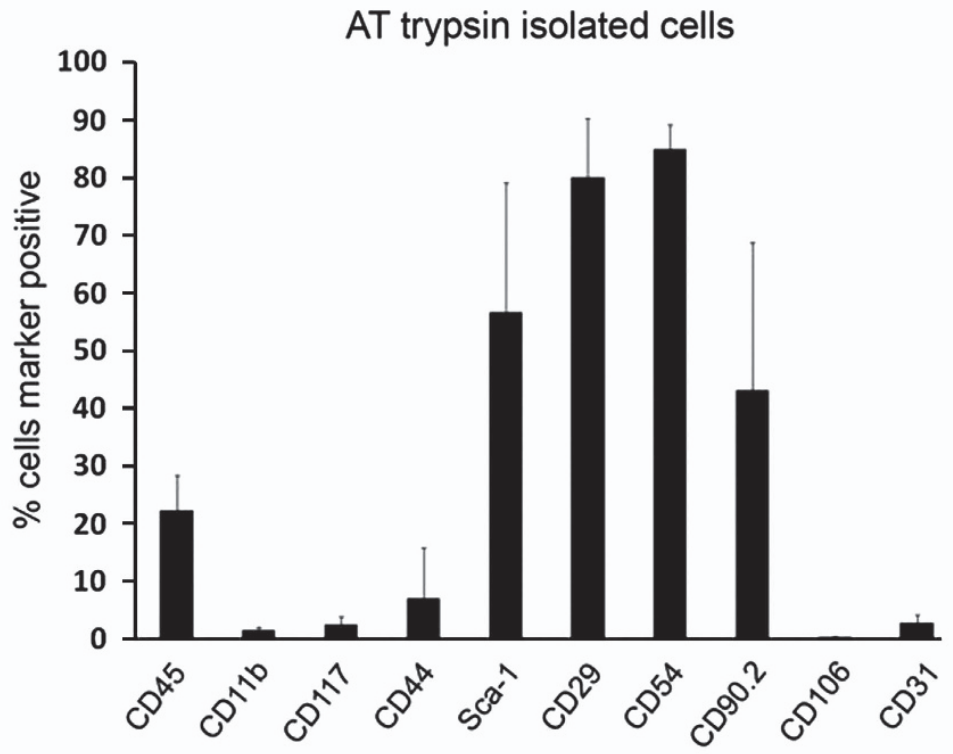

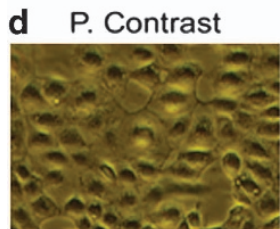
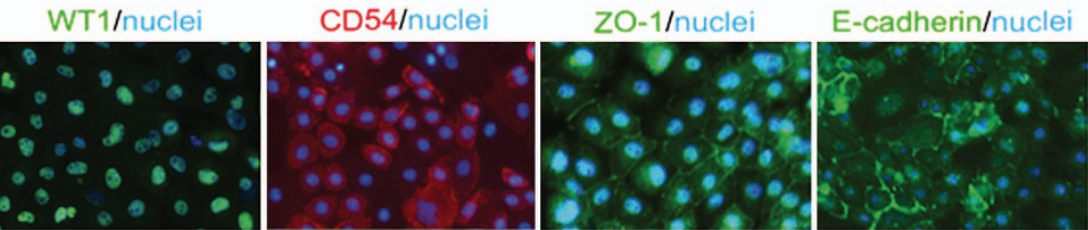

$\beta$-catenin/nuclei

Figure 1 Efficient recovery of ATMCs by gentle trypsinization of the uterine AT. (a) Aspect of uterine AT depots before (left) and after (middle) quirurgical separation from uterine cords. Right photograph shows representative aspect of cells isolated through gentle trypsinization of AT. Trypsin typically detached small sheets (spot) of flattened epitheloid cells that adopted 'grape-like' structure after full retraction. (b) Trypsin isolated cells widely immunoexpressed epithelial ( $\beta$-catenin, E-cadherin and ZO-1) and CD54. They also immunoexpressed more heterogeneously Sca1 and lacked expression of the VSMCs marker smoothelin-B (Smtn-B). (c) Flow cytometry analysis expression results of several surface markers in trypsin isolated cells $(n=5)$. (d) Trypsin isolated cells cultured for 5 days in BMe exhibited cobblestone morphologies (phase contrast) and immunoexpressed WT1, CD54, ZO-1, E-cadherin and $\beta$-catenin. (b and $\mathbf{d}$ ) Nuclei are counterstained in blue with Hoechst 33342

In further confirmation of their initiation of a vasculogenic EMT, qPCR analysis also demonstrated that the EGFinduced ATMCs displayed in distinct degrees a clear upexpression of the SM genes calponin, $\alpha$-SMA, SM22 $\alpha$, desmin, SM-MHC and h-caldesmon through time culture (Figure 3a).

Early EGF-induced ATMCs acquire expression of a subset of cardiac muscle markers. Interestingly, the EGF-induced ATMCs also displayed significant up-expression of the cardiac genes cTnT, SERCA2 and MLC2a (Figure 3d).
Other genes expressed during cardiomyogenesis (BPM2, Flk1, c-Kit, Isl1, Hrt1, Tbx5 and Nkx2.5) and in mature cardiomyocytes (cTnl, MHC- $\beta$ and ANF) were by contrast strongly downregulated in the early EGF-induced ATMCs, suggesting hence that they were not undergoing an accurate cardiomyogenic differentiation program (Figure 3e). Supporting these findings are also western blot analysis experiments of the EGF-induced ATMCs, which clearly evidenced their strong up-expression of PDGFR- $\beta, \alpha$-SMA and Smtn-B through time culture, finding that is consistent with the emergence of a VSMCs phenotype (Figure 4b). Although 

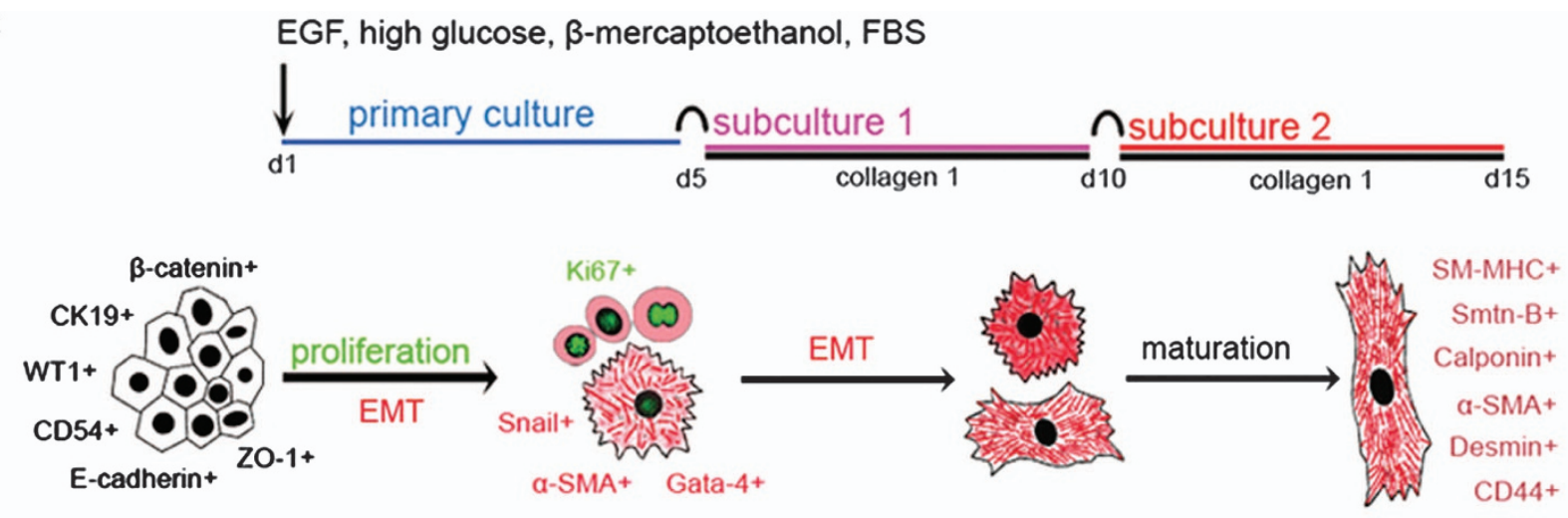

AT mesothelium

cellular intermediates

vascular smooth muscle-like

b
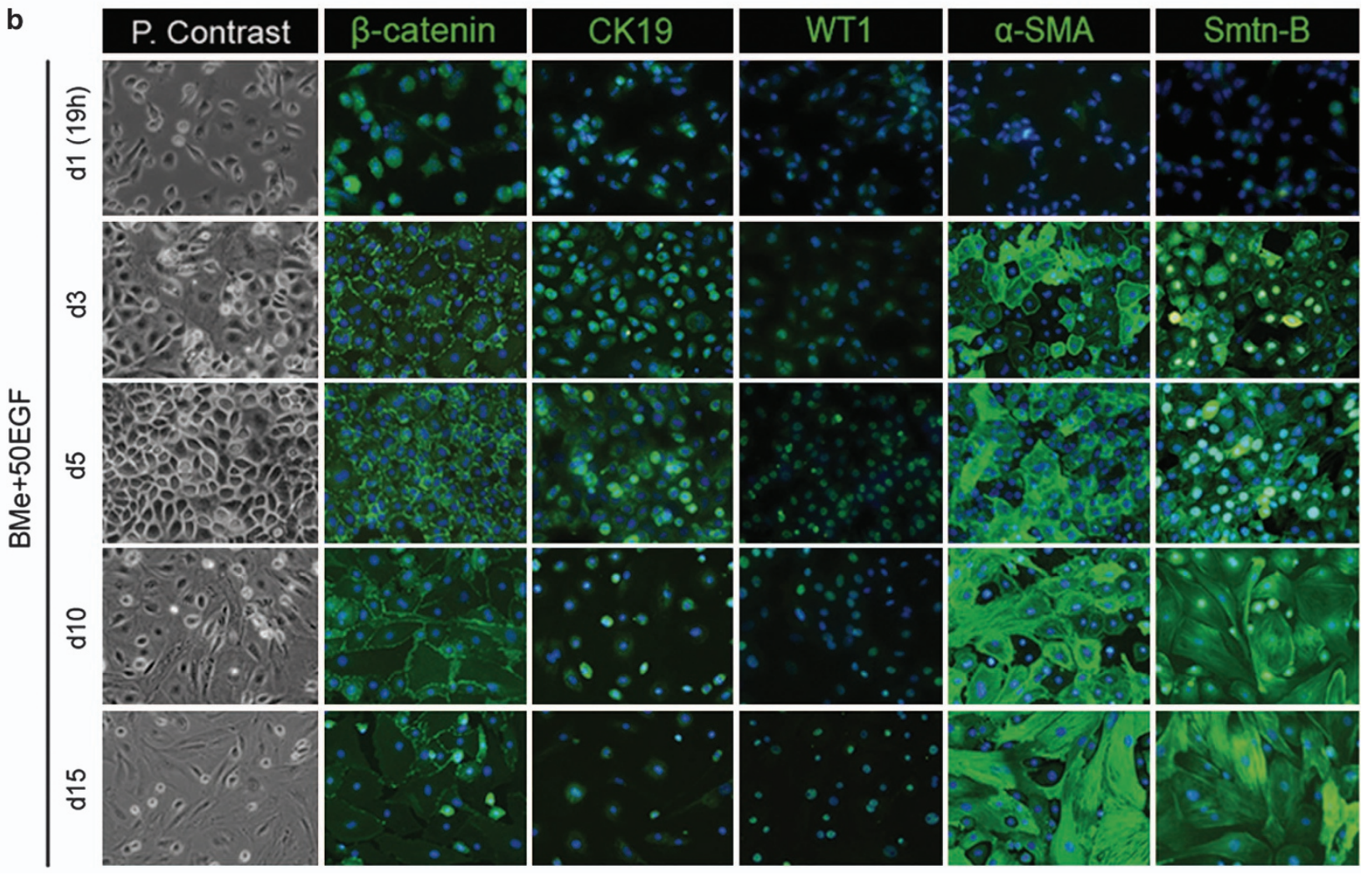

Figure 2 Efficient transdifferentiation of ATMCs towards VSM-like cells through subsequent subculture into BMe $+50 E G F$. (a) Schematic representation of the stepwise protocol used to direct ATMCs towards VSM-like cells. (b) Immunofluorescence characterization of ATMCs transdifferentiation towards VSM-like cells. Left images show representative phase contrast pictures of ATMCs cultured for 1, 3,5, 10 and 15 days in BMe +50EGF. Left to right, shows corresponding immunofluorescence expression patterns against epithelial ( $\beta$-catenin and CK19), mesothelial (WT1) and VSMCs ( $\alpha$-SMA and Smtn-B) markers

the expression of cardiac transcription factor Gata-4 was progressively upregulated through time culture, the EGFinduced ATMCs, however, only minimally acquired expression of the cardiac markers SACTN and CTnT (Figure 4c).

Interestingly, double immunofluorescence labellings could corroborate the dual VSMCs and cardiomyocytic traits acquired by the early EGF-induced ATMCs, as many of them were found to co-immunoexpress the VSMCs marker Smtn-B together with a low expression of the cardiac contractile proteins SACTN and cTnT (Supplementary Figure 4).
EGF-induced ATMCs display activation of the Erk1/2, PI3/Akt and Smad-dependent (Smad2/3) pathways. We next used western blot analysis to determine the signalling pathways that were activated in the EGF-induced ATMCs. As expected, we found that the EGF-induced ATMCs displayed an active phosphorylation of the EGF receptor (Tyr1068) and of its downstream signalling pathways molecules AKT and ERK1/2 (Figure 4d). Noticeably, the EGF-induced ATMCs also displayed a robust phosphorylation of Smad-2, which is a downstream mediator of TGF $\beta 1$ 
Table 1 Summary of immunofluorescence analysis

\begin{tabular}{|c|c|c|c|c|c|}
\hline Antigen & Lineage distribution & AT mesothelium & ATMCs & EMT & VSM-like cells \\
\hline Mesothelin & Mesothelial and epithelial & ++ & ++ & +++ & + \\
\hline$\beta$-Catenin & Epithelial, mesothelial and endothelial & ++ & ++ & +++ & $+1++$ \\
\hline $\mathrm{ZO}-1$ & Epithelial, mesothelial and endothelial & + & + & ++ & $+{ }^{*}$ \\
\hline E-cadherin & Epithelial and mesothelial & $+{ }^{*}$ & + & ++ & $+{ }^{*}$ \\
\hline CK18 & Epithelial and mesothelial & $+{ }^{*}$ & + & $-1++$ & $-1+$ \\
\hline CK19 & Epithelial and mesothelial & ND & $+1++$ & +++ & $-1++$ \\
\hline WT1 & Mesothelial & + & + & ++ & $-1++$ \\
\hline Vimentin & Mesenchymal & ND & ++ & +++ & +++ \\
\hline Desmin & SM, myofibroblasts and cardiac & ND & $+{ }^{*}$ & $+1++$ & ++ \\
\hline$\alpha-S M A$ & SMCs, myofibroblasts and myoepithelial & - & - & $++1+++$ & +++ \\
\hline Calponin & SMCs, myofibroblasts and myoepithelial & ND & - & ++ & $++1+++$ \\
\hline $\operatorname{SM} 22 \alpha$ & SMCs, myofibroblasts and myoepithelial & ND & - & $-1+$ & $++1+++$ \\
\hline SM-myosin & SMCs, myofibroblasts and myoepithelial & ND & - & +++ & +++ \\
\hline Caldesmon & SMCs, myoepithelial cells and mesothelial & ND & $+{ }^{*}$ & ++ & $++1+++$ \\
\hline Smtn-B & Vascular SM & $+{ }^{*}$ & $+t^{*}$ & ++ & +++ \\
\hline PDGFR $\beta$ & SM and cardiac & ND & $+{ }^{*}$ & ++ & $++1+++$ \\
\hline Gata-4 & Cardiac and SM progenitors & ND & - & ++ & $++1+++$ \\
\hline Isl1 & Progenitors & ND & + & $+1++$ & + \\
\hline cTnT & Cardiac & ND & - & ++ & $+/++$ \\
\hline SACTN & Cardiac & ND & - & $+1++$ & $++1+++$ \\
\hline Ki67 & Proliferating cells & ND & - & +++ & + \\
\hline Nestin & Neuronal and SM progenitors & ND & - & $++1+++$ & $+1++$ \\
\hline CD45 & Haematopoietic cells & $-1+$ & $-1+$ & - & - \\
\hline CD11b & Monocytes and macrophages & - & - & - & - \\
\hline Sca1 & Microvascular endothelial and progenitors & $+{ }^{*} /+$ & $+* /++$ & - & - \\
\hline CD44 & Stromal & $+{ }^{*}$ & $+{ }^{*}$ & + & $+/++$ \\
\hline CD106 & Stromal mesenchymal and endothelial & - & - & - & - \\
\hline CD117 & Haematopoietic and cardiac progenitors & - & - & - & - \\
\hline CD54 & Endothelial and mesothelial & +++ & +++ & ++ & $+/++$ \\
\hline CD29 & Mesenchymal, epithelial and mesothelial & $+1++$ & $+1++$ & +++ & +++ \\
\hline CD31 & Endothelial & - & - & - & - \\
\hline CD90.2 & Epithelial and mesenchymal & $+{ }^{*} /+$ & $+{ }^{*} /+$ & $+/++$ & $+/+++$ \\
\hline
\end{tabular}

Abbreviations: $\alpha$-SMA, alpha smooth muscle actin; CK18 and CK19, cytokeratins 18 and 19; cTnT, cardiac troponin T; HCAM, homing cell adhesion molecule; ICAM-1, intercellular cell adhesion molecule 1 ; LCA, leukocyte common antigen; ND, not done; PECAM-1, platelet endothelial cell adhesion molecule 1; PDGFR- $\beta$, platelet-derived growth factor receptor beta; sACTN, sarcomeric alpha actinin; Smtn-B, smoothelin B; VCAM-1, vascular cell adhesion molecule 1; WT1, Wilms tumour protein 1; ZO-1, zona occludens 1

Immunofluorescence degrees:-, negative; + *, very weak; +, weak; + +, intermediate; + + +, strong; EMT and VSM-like cells correspond to ATMCs cultured for 5 and 15 days in BMe $+50 E G F$, respectively

signalling, ${ }^{24,34}$ suggesting thus that the EGF-induced ATMCs may secrete TGF $\beta 1$ in a paracrine manner.

EGF-induced ATMCs acquire characteristics of differentiated VSMCs through sequential subculture. Sequential subculture of the EGF-induced ATMCs at decreasing seeding density onto a collagen I-coated surface resulted in a drastic loss of their proliferation (Supplementary Figure 2) favouring in turn their maturation towards VSM-like cells as evidenced by their robust increase in expression of the SM genes calponin, $\alpha$-SMA, SM22 $\alpha$, desmin, SM-MHC and h-caldesmon evidenced by qPCR analysis (Figure $3 c$ ). A strong up-expression of these SM markers through subculture steps 1 and 2 could also be confirmed at the protein level by immunofluorescence (Figure $2 b$ and Supplementary Figure 3) and flow cytometry (Figure 5a and Supplementary Figure 5a) approaches. Western blot analysis also indicated a strong up-expression of $\alpha$-SMA, PDGFR- $\beta$ and Smtn-B during subculture steps 1 and 2 , markers that are consistent with the establishment in subculture of a mature VSMC-like phenotype (Figure 4b).

In addition, the EGF-induced ATMCs also increased moderately their expression of the cardiac genes CTnT and MLC2a during subculture (Figure 3c). By contrast, other genes expressed during early cardiomyogenesis (BPM2,
Flk1, c-Kit, Isl1, Hrt1, Tbx5 and Nkx2.5) and in mature cardiomyocytes (cTnl, MHC- $\beta$ and ANF) remained strongly downregulated through subculture steps 1 and 2 (Figure 3d).

Flow cytometry analysis was also performed to determine whether the vasculogenic differentiation undertaken by the EGF-induced ATMCs is associated with significant changes in their cell surface marker phenotype (Figure $5 \mathrm{~b}$ and Supplementary Figure 4b). Consistent with their loss of mesothelial characteristics through subculture steps, the EGF-induced ATMCs displayed significant loss of CD54 expression from days 5 to 15 of culture $(P<0.01)$. In turn, CD44, a marker constitutively expressed on $\mathrm{SMCs}^{35}$ was found to be significantly upregulated through subculture $(P<0.01)$.

EGF sequentially improves the proliferation and vasculogenic differentiation of ATMCs. Growth curves of ATMCs cultured for 15 days in BMe or BMe $+50 E G F$ were established (Supplementary Figure 2a) and fold increase in cell numbers calculated at the end of each culture steps (Supplementary Figure 2b). Comparative cell counts indicated that ATMCs primary cultured in BMe $+50 E G F$ proliferated more actively than in BMe cultures (5.64 \pm 0.35 versus $3.56 \pm 0.2$-fold increase, respectively, $P<0.001$; Supplementary Figure 2b). Such difference was, however, 
Freshly isolated ATMCs

a

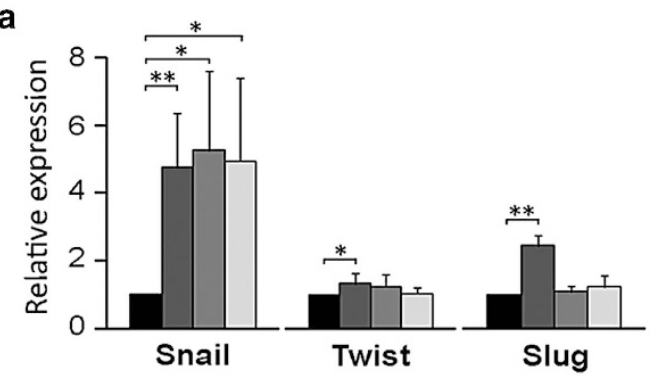

day $5 \quad \square$ day $10 \quad \square$ day 15

b

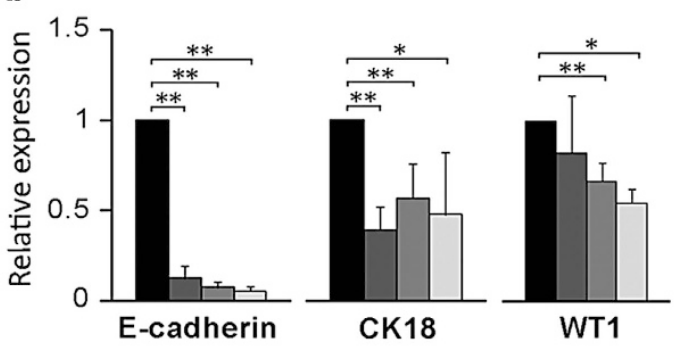

c
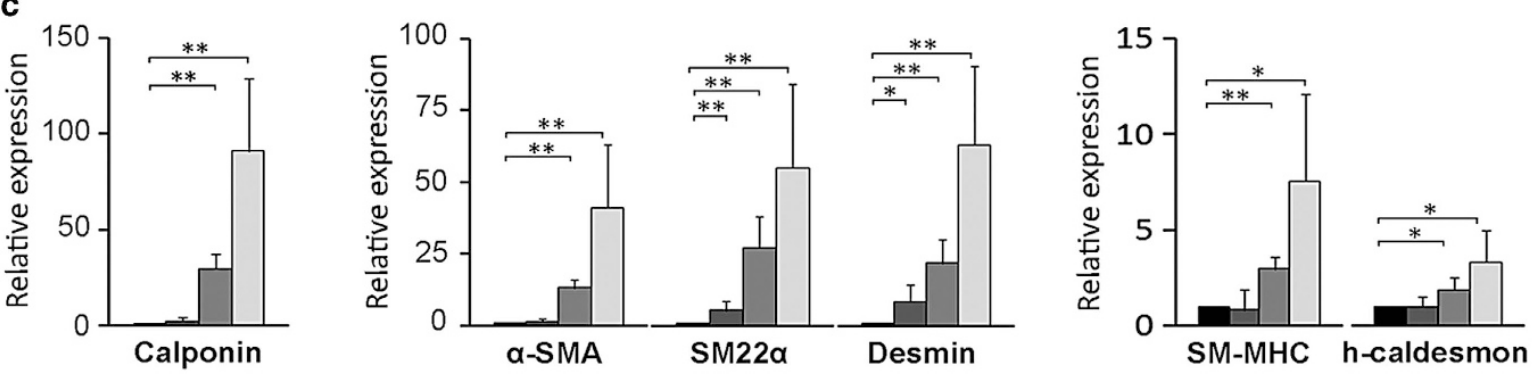

d
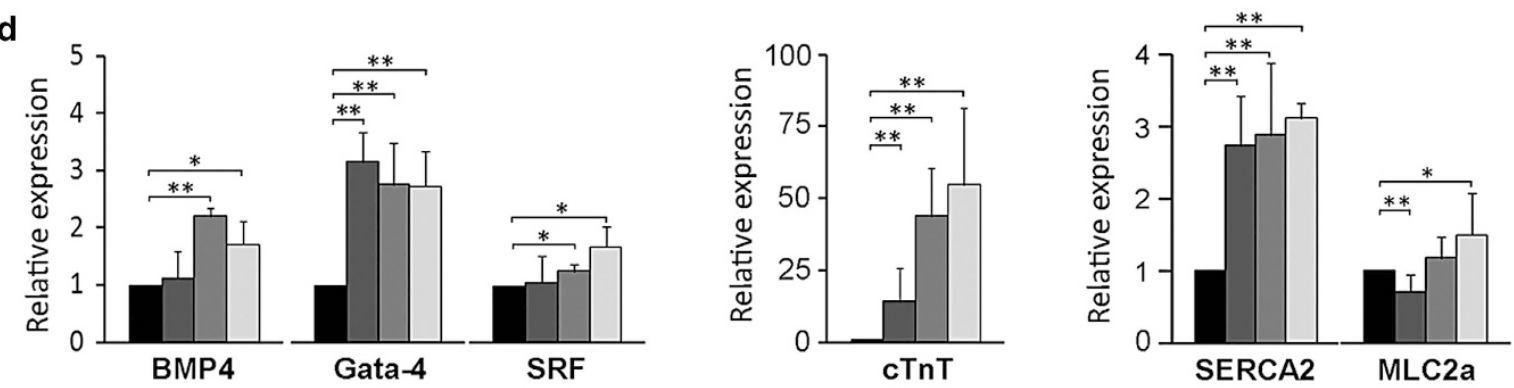

e
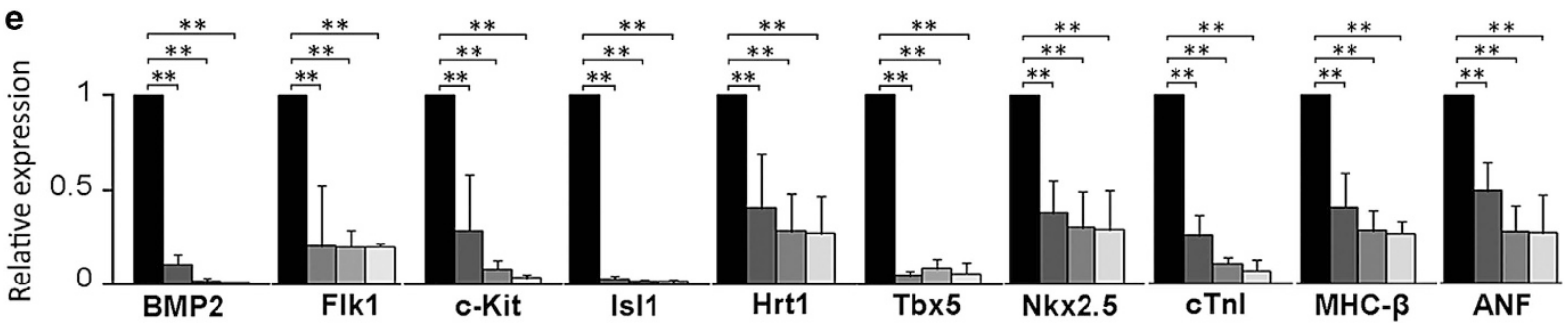

Figure 3 Quantitative RT-PCR analysis of the mRNA expression profile of ATMCs cultured into BMe $+50 E G F$. The expression patterns of EMT (a), mesothelial (b), SM (c) and cardiac (d and e) genes was compared between ATMCs cultured for 5, 10 and 15 days in BMe + 50EGF and the freshly isolated ATMCs (black bars), which served as the calibrator sample. Gene expression was normalized against expression levels of the housekeeping gene TBP. Results shown are the mean fold change \pm S.D. in mRNA expression relative to the calibrator sample (set as 1) calculated from three independent enzymatic isolation of ATMCs and cultures into BMe $+50 E G F$. Statistical significance $\left({ }^{\star} P<0.05\right.$ and $\left.{ }^{*} P<0.03\right)$ was determined by using Student's $t$-test

strongly reduced through their first subculture step $(2.9 \pm 0.36$ versus $2.45 \pm 0.29$-fold increase, respectively, $P<0.05)$ and finally became insignificant through their second subculture step when cells drastically reduced their proliferation as also indicated by Ki67 staining (Supplementary Figure 2c).

ATMCs subcultured in BMe +50 EGF were mainly fibroblastoid with prominent $\alpha$-SMA ${ }^{+}$stress fibres (Supplementary Figure 6a). In turn, ATMCs subcultured in BMe rather displayed epitheloid morphologies with only a minor subset displaying transitional epitheloid-fibroblastoid appearance. The partial SM differentiation of ATMCs subcultured in BMe was also reflected on the basis of their diffuse $\alpha$-SMA cytoplasmic pattern. Correlating with this finding, collagen gel lattices harbouring ATMCs subcultured in BMe + 50EGF contracted in significantly higher extent $(P<0.01)$ than did collagen gel lattices containing equal numbers of ATMCs subcultured in BMe (Supplementary Figure 6b). 
a
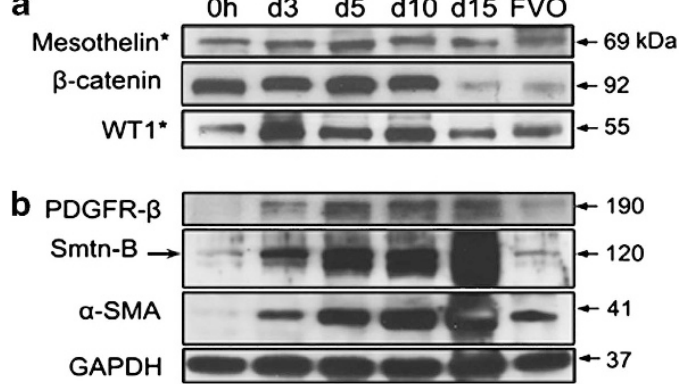

C

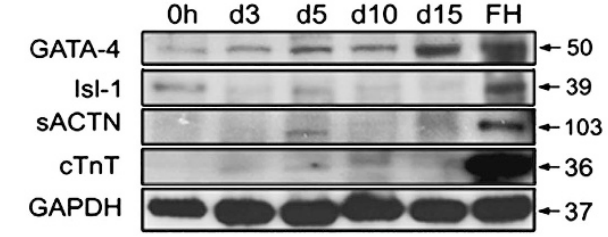

d

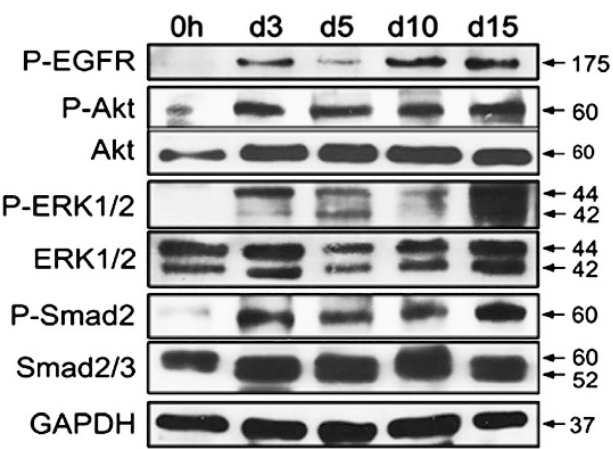

Figure 4 Western blotting analysis of phenotypic changes undertaken by ATMCs upon sequential subculture into BMe $+50 E G F$. Expression of markers expressed in the mesothelial (a), SM (b) and cardiac (c) lineages as well as the phosphorylation pattern of the EGF receptor, Akt, ERK1/2 and Smad2 (d) were evaluated in freshly isolated ATMCs $(0 \mathrm{~h})$ and ATMCs after 3, 5, 10 and 15 days of culture in $\mathrm{BMe}+50 \mathrm{EGF}$. FVO, are proteins from mouse fetal (E17) visceral organs (heart, lung and peritoneal organs). $\mathrm{FH}$, are proteins from mouse fetal (E17) hearts

ATMC-derived VSM-like cells display vasoactive agonist-induced contraction. The main function of VSMCs is to contract and relax in response to vasoactive agents. On this basis, we therefore aimed to evaluate the contractile pattern of ATMC-derived VSM-like cells against a wide range of vasoconstrictors (Table 2). To achieve this goal, we used a sensitive contraction model previously developed in our laboratory, ${ }^{18}$ which consisted in the generation of spheroids aggregates of ATMC-derived VSM-like cells through suspension culture (Figure 6a). Replating of spheroids onto an adherent surface allowed spreading cells to actively reorganize in the form of multilayered spindle-shaped cells, which is a cellular organization more closely to that of native contractile SMCs. Immunofluorescence could confirm that the spreading cells retained strong immunoexpression of SM22 $\alpha$, and $\alpha \mathrm{SMA}$ (Figure 6b) as well as of Smtn-B, caldesmon, CD44, CD29 and CD90.2 (Supplementary Figure 7).

We then tested the ability of ATMC-derived VSM-like cells to contract against vasoactive agonists by using time-lapse image recording (Table 2). Consistent with their gain of VSMCs traits, spreading ATMC-derived VSM-like cell spheroids invariantly displayed intermediate to strong contractile responses to $50 \mathrm{nM}$
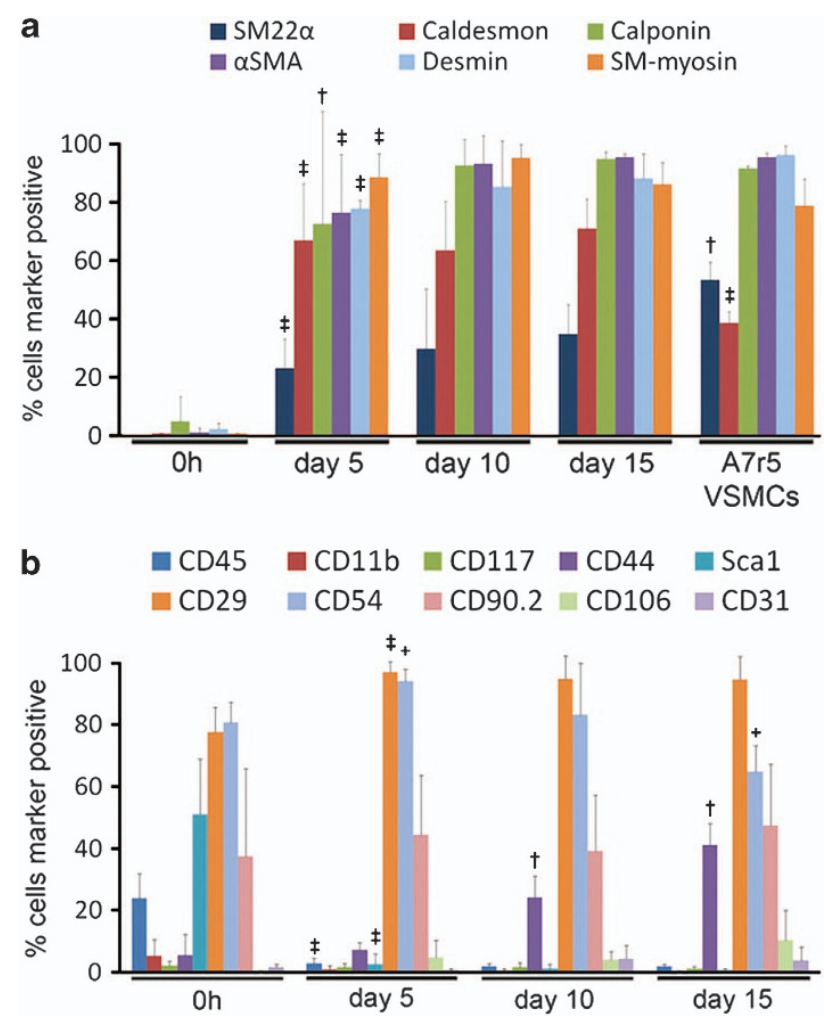

Figure 5 Summary of flow cytometry analysis of SMCs and lineage surface markers expression into BMe $+50 E G F$ cultured ATMCs. (a) Intracellular flow cytometry quantification of cells expressing SMCs markers (SM22 $\alpha$, caldesmon, calponin, $\alpha$-SMA, desmin and SM-myosin) among freshly isolated ATMCs $(0 \mathrm{~h})$, ATMCs cultured for 5,10 and 15 days in BMe $+50 E G F$ and the rat aortic VSMCs line A7r5 VSMCs. (b) Quantification of percentages of cells expressing haematopoietic (CD45 and CD11b), stem cells (CD117), mesenchymal and stromal (CD44, Sca1, CD29, CD54, CD90.2) and endothelial (CD31, CD106) surface markers in freshly isolated ATMCs $(0 \mathrm{~h})$ and ATMCs cultures for 5,10 and 15 days in BMe +50 EGF. (a and $\mathbf{b}$ ) Results were deduced from $n=3$ independent cultures. Significant changes $\left({ }^{+} P<0.05 ;{ }^{\dagger} P<0.03 ;{ }^{\ddagger} P<0.01\right)$ in marker expression suffered by ATMCs through cultures steps (day 5 compared with $0 \mathrm{~h}$; day 10 compared with day 5 and day 15 compared with day 10) were evaluated by using Student's $t$-test. ATMCs cultured for 15 days into BMe $+50 E G F$ were also compared against A7r5 VSMCs

endothelin 1 (Supplementary Movie 1), $60 \mathrm{mM} \mathrm{KCl}$ (Supplementary Movie 2) and $10 \mu \mathrm{M}$ vasopressin (Supplementary Movie 3). Weak to intermediate contractile responses were also recorded against $1 \mathrm{mM}$ carbachol (Supplementary Movie 4), $10 \mu \mathrm{M}$ angiotensin-II (Supplementary Movie 5), $10 \mu \mathrm{M}$ oxytocin, $100 \mu \mathrm{M}$ norepinephrine and $100 \mu \mathrm{M}$ serotonin. For summary of contractile responses see Table 2 .

In most SMCs, the vasoconstrictor effect of endothelin-1 (ET1) is primarily mediated through its binding to the endothelin subtype receptors $\mathrm{ET}_{\mathrm{A}}$ and in much lower extent via $\mathrm{ET}_{\mathrm{B}}$ receptors. ${ }^{36}$ To test whether ATMC-derived VSM-like cells also acquired similar mechanisms, they were preincubated with selective $\mathrm{ET}_{\mathrm{A}}$ and $\mathrm{ET}_{\mathrm{B}}$ receptors antagonists before being challenged against $50 \mathrm{nM}$ ET1 (Table 2). We found that ATMC-derived VSM-like cells preincubated with $1 \mu \mathrm{M} \mathrm{BQ}-123$ (ET $\mathrm{E}_{\mathrm{A}}$ antagonist) displayed only weak contractile responses to $50 \mathrm{nM}$ ET1 (Supplementary Movie 6), while those preincubated with $1 \mu \mathrm{M}$ BQ-788 (ET $T_{\mathrm{B}}$ antagonist) exhibited moderate to strong contraction against $50 \mathrm{nM}$ ET1 
Table 2 Summary of vasoactive agonist-induced contractile responses

\begin{tabular}{|c|c|c|c|}
\hline Vasoactive agonists & ATMC-derived VSM-like cells & Mouse vena cava SMCs & Rat aortic SMCs \\
\hline $\begin{array}{l}\mathrm{dH}_{2} \mathrm{O}+50 \mathrm{nM} \text { ET1 } \\
1 \mu \mathrm{M} \text { BQ123 + 50 nM ET1 } \\
1 \mu \mathrm{M} \text { BQ788 + 50 nM ET1 } \\
1 \mu \mathrm{M} \text { BQ123 + } 1 \mu \mathrm{M} \text { BQ788 + 50 nM ET1 } \\
60 \mathrm{mM} \mathrm{KCl} \\
10 \mu \mathrm{M} \text { Vasopressin } \\
10 \mu \mathrm{M} \text { Oxytocin } \\
100 \mu \mathrm{M} \text { Norepinephrine } \\
100 \mu \mathrm{M} \text { Serotonin } \\
10 \mu \mathrm{M} \text { Angiotensin II } \\
1 \text { mM Carbachol }\end{array}$ & $\begin{aligned} &++(7) \\
&-/+(2) \\
&+(2) \\
&-(2) \\
&+(5) \\
&+ \leftrightarrow++(7) \\
&-/+ \leftrightarrow++(4) \\
&-/+\leftrightarrow++(5) \\
&-/+\leftrightarrow++(4) \\
&-/+\leftrightarrow++(5) \\
&-\leftrightarrow+(5)\end{aligned}$ & $\begin{array}{l}++(1) \\
\text { ND } \\
\text { ND } \\
\text { ND } \\
++(1) \\
++(1) \\
+(1) \\
+(1) \\
+(1) \\
++(1) \\
+(1)\end{array}$ & $\begin{array}{l}+++(1) \\
\text { ND } \\
\text { ND } \\
\text { ND } \\
++(1) \\
+++(1) \\
++(1) \\
+(1) \\
+(1) \\
+++(1) \\
++(1)\end{array}$ \\
\hline
\end{tabular}

Abbreviations: ET-1, endothelin-1; ND, not done

BQ-123 (selective ETA receptors antagonist). BQ-788 (selective ETB receptors antagonist). ( - ), is for a lack of contraction; $(-/+)$, is for a weak contraction; $(+)$, is for a moderate contraction; $(++)$, is for a strong contraction. $\leftrightarrow$, indicates variation in contractile responses between independent cultures. $(n)$, indicates number of independent cultures tested

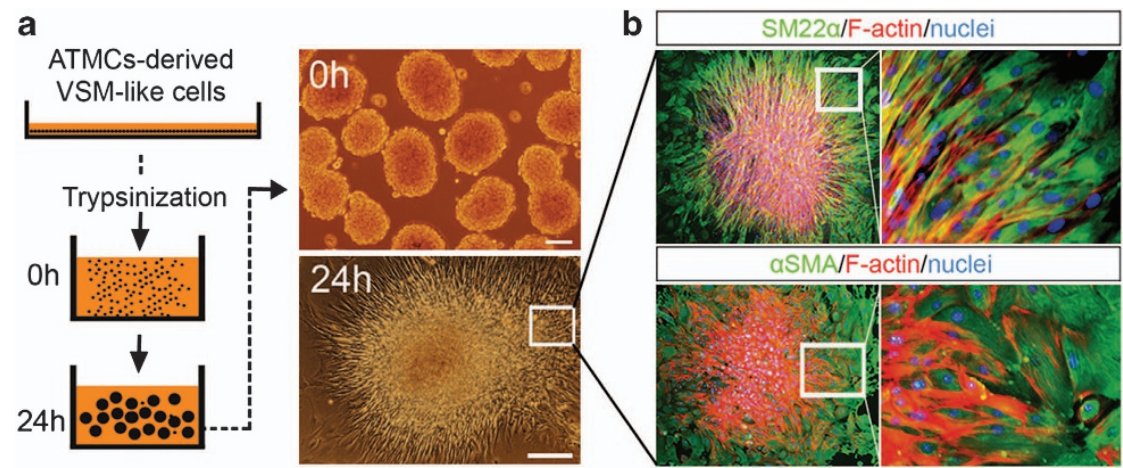

Figure 6 Generation of spreading ATMC-derived VSM-like cell spheroids for their use in contraction studies. (a) Schematic representation of steps performed to generate ATMC-derived VSM-like cell spheroids. Right, phase contrast pictures of spheroid taken after 0 and $24 \mathrm{~h}$ of their transfer onto plastic adherent surface into BMe $+50 \mathrm{EGF}$. Scale bar is $200 \mu \mathrm{m}$. (b) Immunofluorescence characterization of SMCs markers (SM22 $\alpha$ and $\alpha$ SMA) expression in spheroids fixed after $24 \mathrm{~h}$ of spreading onto plastic surface

(Supplementary Movie 7). Only a combined preincubation with both $1 \mu \mathrm{M}$ BQ-123 and $1 \mu \mathrm{M} \mathrm{BQ}-788$ could efficiently abolish their ET1-induced contraction (Supplementary Movie 8). Collectively, our results indicate that similarly observed in most SMCs, ET1 mediates its vasoconstrictive action in ATMC-derived VSM-like cells principally by acting through $E T_{A}$ receptors and in much lower extent through $E T_{B}$ receptors.

\section{Discussion}

The transdifferentiation protocol described here could efficiently induced ATMCs to acquire molecular and functional traits of differentiated VSMCs. This goal was achieved by subjecting ATMCs to basal provasculogenic inductive culture with serum ${ }^{17}$ and in combination with EMT-inducing factors such as high glucose ${ }^{37,38}$ and EGF. ${ }^{17,39}$ The vasculogenic differentiation of primary cultured ATMCs was further improved towards VSMCs through repetitive disruption of cell-cell interactions through sequential subculture steps and at decreasing seeding density onto a collagen I-coated surface. Their maturation towards differentiated VSMCs was finally achieved through a step of cellular reaggregation under suspension culture to generate a multilayered cellular structure mimicking more closely the organization of native SMCs.
We provide here evidences that EGF exerts both mitogenic and EMT-inducing activities into serum-cultured ATMCs. EGF mainly exerted a mitogenic effect on a subset of ATMCs in early phases of culture, whereas its EMT-inducing activity was rather patent during subculture. Accordingly, EGF was previously shown to display potent mitogenic activity onto peritoneal MCs. ${ }^{40}$ Although previous reports also identified the EMTinducing activity of distinct morphogenic growth factors such as TGF- $\beta 1$, bFGF and PDGF-BB onto serum-cultured adult MCs, leading to their transdifferentiation into $\alpha-\mathrm{SMA}^{+}, \mathrm{SM}^{-m y o s i n}{ }^{+}$ and desmin ${ }^{+}$SM-like cells, none of them addressed their functional status to determine whether they had acquired molecular and functional characteristics of VSMCs. ${ }^{16,17,22-24}$

The finding that the early EGF-induced ATMCs expressed markers consistent with progenitor cells (Gata-4, CD133 and nestin), cardiomyocytes (sACTN, cTnT, SERCA2 and MLC2a) and VSMCs ( $\alpha$-SMA, calponin, caldesmon, SM22 $\alpha$, desmin, SM-MHC, smoothelin-B and PDGFR- $\beta$ ) led us to hypothesize that distinct subsets of the EGF-induced ATMCs initiated vasculogenic and cardiomyocytic differentiation program. Our detailed qPCR analysis, however, evidenced a clear down expression in the early EGF-induced cardiac progenitors markers Isl1, C-Kit, Flk-1 and Nkx2.5 $5,6,41$ and of BMP2, Tbx5 and Hrt1, which are involved during early cardiac development, finding that may clearly exclude the emergence in their culture of a cardiac progenitor population. 
The coexpression of cardiac and VSMCs markers in part of the EGF-induced ATMCs rather support the hypothesis that only specific cardiac markers are expressed during the vasculogenic differentiation of MCs. In strong support of this emerging concept is a previous report that indicated how human epicardial MCs subjected to serum culture coexpressed the SM markers $\alpha$-SMA and SM-MHC together with the cardiac markers Gata-4, cTnT and Cx43. ${ }^{16}$ In further support of this finding, we also previously observed similar coexpression pattern in murine UtMCs subjected to provasculogenic inductive conditions. ${ }^{18}$ Collectively, the confirmation of similar findings in MCs isolated from three distinct mesotheliums (heart, uterus and AT) strongly suggests that the adult mesothelial lineage could retain intrinsic bipotency to perform cardiomyogenic and leiomyogenic differentiation depending on specific inductive stimuli. Further studies to decipher putative cardiomyogenic inductive mechanisms for adult MCs are under progress.

The coexpression of Isl-1 and SM-MHC in the early EGFinduced ATMCs is very interesting because these markers identify a population of VSMCs progenitors in the developing human heart $^{42}$ and in differentiating ESCs cultures. ${ }^{5,6}$ Interestingly, the early EGF-induced ATMCs were also found to gain expression of the neural and progenitor cell marker nestin, which is transiently expressed in VSMCs progenitors of rat embryonic arteries. ${ }^{43}$ Collectively, the wide expression of IsI1, SM-MHC, nestin and Smtn-B in the majority of the early EGF-induced ATMCs is an unequivocal evidence of their gain of traits of VSMCs progenitors, a finding which is in strong support that adult ATMCs retain vasculogenic potential similar to embryonic MCs.

The fact that our differentiation protocol could force ATMCs to recapitulate an accurate leiomyogenic differentiation program is unequivocally provided on the basis of the acquisition of both molecular markers (PDGFR- $\beta, \alpha$-SMA, calponin, h-caldesmon, SM $22 \alpha$, desmin, SM-MHC and Smtn-B) and functional hallmarks of differentiated VSMCs (contractile responses to voltage (high $\mathrm{K}^{+}$) and receptors (ET1, vasopressin, oxytocin, noradrenaline, serotonin, angiotensin-II and carbachol)-induced contraction). We previously described the acquisition of similar contractile mechanisms in UtMC-derived VSM-like cells. ${ }^{18}$ Interestingly, both uterine MC- and ATMC-derived VSM-like cells displayed the strongest contractile responses recorded when stimulated with the potent vasoconstrictor ET-1, which was shown to exert its action principally through $\mathrm{ET}_{\mathrm{A}}$ receptors, which is the typical mechanism of action of ET1 in most native SMCs types. ${ }^{36}$ Again, these findings obtained from two distinct mesotheliums strongly support the concept that indistinctly of their anatomical origin, adult visceral MCs retain intrinsic potency to transdifferentiate into VSMCs.

Overall, our results show that EGF signalling activation potentiates the vasculogenic differentiation of serum-cultured ATMCs, leading to their transdifferentiation towards functional VSMC-like cells. Mechanistically, EGF signalling activation was evidenced by an active phosphorylation of the EGF receptor and the phosphorylation of its downstream signalling pathways Erk1/2 and PI3K/Akt. Supporting our results, a previous study already reported the active phosphorylation of Erk1/2 and Akt in human ovarian MCs induced to undergo
EMT in response to their culture in a media containing $10 \mathrm{ng} / \mathrm{ml}$ EGF and $1 \mu \mathrm{g} / \mathrm{ml}$ hydrocortisone. ${ }^{39}$ Furthermore, phosphorylation of Erk1/2 and Akt was also reported in EGF-induced proliferation of human bone marrow MSCs. ${ }^{44}$

Strikingly, the EGF-induced ATMCs also displayed activation of the Smad-dependent (Smad2/3) pathway, a pathway that was previously reported to be activated in adult human pleural and peritoneal MCs undergoing EMT in response to TGF- $\beta 1$ signalling. ${ }^{24,34,45}$ Interestingly, a previous study indicated that high glucose was sufficient by itself to induce an autocrine production of TGF- $\beta 1$ in cultured human peritoneal $\mathrm{MCs}^{46}$ and could therefore be a main effector of the activation of the Smad-dependent pathway in our culture model that is using a BMe.

\section{Materials and Methods}

Formulation of BMe and BMe $+50 E G F$ media. BMe is a DMEM GlutaMax high glucose $(4.5 \mathrm{~g} / \mathrm{l})$ containing $25 \mathrm{mM}$ HEPES medium (Gibco, Grand Island, NY, USA; 32430), 10\% heat inactivated fetal bovine serum (GE Healthcare Life Sciences, HyClone Laboratories, Logan, UT, USA), 1\% penicillin streptomycin (Gibco), $100 \mu \mathrm{M} \beta$-mercaptoethanol (Gibco, 31350-010). BMe +50EGF is BMe supplemented with $50 \mathrm{ng} / \mathrm{ml}$ of mouse recombinant EGF (PeproTech, Rocky Hill, NJ, USA; 315-09).

Isolation and culture of ATMCs. Visceral AT was isolated from sexually mature non-pregnant OF1 adult female mice (6-24 weeks old). Guidelines for the animal research protocols were established and approved by the Animal Experimentation and Ethics Committee of CABIMER (CEEA-CABIMER) approved the procedure (permit number 19-2010). ATMCs were obtained by incubating AT depots in PBS containing $2 \%$ bovine serum albumin (BSA) and $0.25 \%$ trypsin (Gibco) in a water bath at $37^{\circ} \mathrm{C}$ for $20 \mathrm{~min}$. In all, $3 \times 10^{5}$ ATMCs were plated per well $\left(3.5 \times 10^{4} \mathrm{cells} / \mathrm{cm}^{2}\right)$ of a six-well tissue culture dishes (Nunc, Roskilde, Denmark) into $2 \mathrm{ml} \mathrm{BMe}+50 \mathrm{EGF}$ and placed in an incubator $\left(5 \% \mathrm{CO}_{2}, 37^{\circ} \mathrm{C}\right)$. Media were eliminated after $24 \mathrm{~h}$ to remove unbound cells and debris and then exchanged every $48 \mathrm{~h}$. ATMCs were then harvested after 5 days of culture with $0.05 \%$ trypsin and replated at $1.5 \times 10^{4} \mathrm{cells} / \mathrm{cm}^{2}$ in BMe +50 EGF into Petri dishes $(140 \mathrm{~mm}$, Nunclon $\Delta$ Surface, Nunc) coated with $1 \mathrm{mg} / \mathrm{ml}$ collagen type I (C3867, Sigma-Aldrich, St. Louis, MO, USA) and subcultured for other 5 days. After this, ATMCs were harvested and replated at $10^{4} \mathrm{cells} / \mathrm{cm}^{2}$ into $140 \mathrm{~mm}$ Petri dishes coated with collagen type I and containing BMe $+50 E G F$ and subcultured again for other 5 days of duration.

Isolation and culture of primary rat aortic SMCs. Aortas were isolated from Wistar adult rats with fine scissors, washed in PBS and incubated for $10 \mathrm{~min}$ in a $0.25 \%$ trypsin solution containing $2 \%$ BSA to detach perivascular and endothelial cells. Aortas were then cut into small pieces and partially digested during $10 \mathrm{~min}$ in a $2 \mathrm{mg} / \mathrm{ml}$ collagenase type-lA solution to obtain fragments of medial SM layer. SM fragments were then transferred to a four-well dish (Nunc Multidishes, Nunc, 176740) containing $400 \mathrm{ml}$ of BMe. Media were partially changed after $24 \mathrm{~h}$. On day 2, once fragments had firmly adhered to the substrate, the volume of media was completed to $1 \mathrm{ml}$. Migrating VSMCs were observable at days 3-4 and cultured until they reached confluence and they were harvested with $0.05 \%$ trypsin. VSMCs were subcultured at $0.5 \times 10^{4} / \mathrm{cm}^{2}$ for other 7 days in BMe and finally used to generate multilayered primary VSMCs cultures for their use in contraction experiments.

Isolation and culture of primary mouse vena cava SMCs. Inferior vena cava were isolated from CD1 adult female mice and cut into segments of $2 \mathrm{~mm}$ length that were incubated into PBS containing $0.25 \%$ trypsin and $2 \%$ BSA to detach perivascular and endothelial cells. Segments were then transferred into a $2 \mathrm{mg} / \mathrm{ml}$ collagenase $I A$ solution and only partially digested during $10 \mathrm{~min}$. Resulting fragments were then collected and replated for explants culture onto collagen I-coated $60 \mathrm{~mm}$ Petri dish into BMe media formulation. SMCs reached confluence after 7 days of culture and were harvested for the generation of spheroids and multilayered cultures for contraction as explained below for the generation of ATMC-derived VSM-like cells multilayered cultures. 
Immunofluorescence. For immunofluorescence procedures, ATMCs were cultured into hydrophilic $\mu$-Dish (Ibidi GmbH, Martinsried, Germany) following the culture protocol described previously. For cell surface antigens, cells were fixed with $4 \%$ (wt/vol) paraformaldehyde. For intracellular antigens, cells were either permeabilized with $0.5 \%$ Triton X-100 or with cold methanol (see Supplementary Table S1). Blocking was done in PBS $+3 \%$ BSA. Fluorescence images were captured with an inverted fluorescence microscope Olympus IX71 equipped with DPController and DPManager softwares (Olympus; www.olympus.co.uk). Nuclei were counterstained with Hoechst 33342 (Sigma-Aldrich). F-actin was stained with an Alexa Fluor 633 phalloidin antibody (Invitrogen, Carlsbad, CA, USA; A22284). Primary and secondary antibodies used in this study are listed in Supplementary Tables S1 and S2, respectively.

Whole-mount immunofluorescence. Freshly isolated AT depots were fixed for $20 \mathrm{~min}$ in PBS containing $4 \%$ paraformaldehyde at $4{ }^{\circ} \mathrm{C}$. AT depots were then washed twice in PBS and cut into several pieces that were finally distributed into a 24-well non-adherent plate. Samples were processed following the same procedures as explained for immunofluorescence detection of surface and intracellular markers. Nuclei were counterstained in PBS containing $1 \mu \mathrm{g} / \mathrm{ml}$ Hoechst 33342. Immunolabelled AT fragments were then finally mounted in sandwich between two glass coverslips and immunofluorescent images were taken with an inverted fluorescence microscope Olympus IX71.

Flow cytometry. For intracellular antigens, cells were permeabilized with $0.5 \%$ Triton X-100 and stained with primary and secondary antibodies listed in Supplementary Tables $\mathrm{S} 1$ and $\mathrm{S} 2$, respectively. For surface antigens detection, cells were fixed with $4 \%$ paraformaldehyde and stained in PBS $+3 \%$ BSA containing conjugated antibodies listed in Supplementary Table S3. Flow cytometry analysis was performed with the use of a FACSCalibur Flow Cytometer (BD FACSCalibur cytometry System, San Jose, CA, USA).

Generation of multilayered ATMC-derived VSM-like cell spheroid cultures. ATMC-derived VSM-like cells (ATMCs isolated after 15 days of subculture in $B M e+50 E G F)$ were cultured $\left(2 \times 10^{6}\right.$ cells in $5 \mathrm{ml} \mathrm{BMe}+50$ EGF per well) in an Ultra Low Attachment Plate (Costar, Thermo Fisher Scientific Inc., Waltham, MA, USA; 3471) for $24 \mathrm{~h}$ to generate spheroids. A volume of $1.3 \mathrm{ml}$ $\mathrm{BME}+50 \mathrm{EGF}$ media containing \pm 50 spheroids was then transferred in each well of a four-well plastic adherent culture dish (Nunc). Spheroids were pooled to the centre of the well and cultured for a period of $24 \mathrm{~h}$ to initiate their spreading.

Time-lapse image recording. Vasoactive agonist-induced contraction of spreading ATMC-derived VSM-like cell spheroids was determined by using timelapse image recording with the use of an inverted microscope Olympus IX71 having a prewarmed $\left( \pm 37^{\circ} \mathrm{C}\right)$ working area as previously described. ${ }^{18}$ Phase contrast images were taken at intervals of $20 \mathrm{~s}$ for a total duration of $20 \mathrm{~min}$. Premixed vasoactive agonists were added after $5 \mathrm{~min}$ of time-lapse recording. Movies were produced from the sequence of phase contrast images recorded.

Collagen gel lattices contraction assay. We used a cell-collagen gel lattice contraction assay to assess the contractile capacity of freshly isolated ATMCs and of ATMCs cultured for 15 days in BMe or BMe + 50EGF (ATMCderived VSM-like cells). Cell suspensions were adjusted to $10^{6} \mathrm{cells} / \mathrm{ml}$ in cold $2 \mathrm{X}$ $\alpha$-MEM (Sigma-Aldrich, M0644) and adjusted to proportion 1:1 with a precooled $4.6 \mathrm{mg} / \mathrm{ml}$ rat tail collagen type I solution (BD Biosciences, San Jose, CA, USA; 354236). A volume of $750 \mu \mathrm{l}$ of each cell-collagen mixture was poured per well of a 12-multiwells tissue culture plate (NunclonTM $\Delta$ Surface, Nunc, 150628) and allowed to polymerize at $37^{\circ} \mathrm{C}$ for $30 \mathrm{~min}$. Lattices were mechanically released from the well by gentle addition of $1 \mathrm{ml}$ of BMe in each well. Digital photographs of collagen gel lattices were taken after $24 \mathrm{~h}$ of their release from the well and used to quantify lattices areas with MetaMorph Software (Molecular Devices Corporation, Downingtown, PA, USA). Results are expressed as the mean \pm S.D. of three independent experiments.

Vasoactive agonists and antagonists. Vasoactive agonists were: $\mathrm{KCl}$ (60128), carbachol (C4382), endothelin 1 (E7764), angiotensin II (A9525), $\left[\mathrm{Arg}^{8}\right]$ arginine vasopressin (V9879), oxytocin (O3251), norepinephrine (A9512) and serotonin (H9523). Antagonists used were atropine (A0132), BQ-123 (B150) and BQ-788 (B157). All were purchased from Sigma-Aldrich.
RNA extraction and qPCR analysis. Total RNA content was extracted with Trizol reagent (Invitrogen), and total RNA (1 $\mu \mathrm{g})$ was reverse-transcribed into cDNA by using MMLV reverse transcriptase (Promega, Madison, WI, USA). qPCR was performed using SYBR-Green and detected using an ABI Prism 7500 system (Applied Biosystems, Foster City, CA, USA). Quantification of the mRNA level of each gene was normalized to TBP mRNA (D101-D136, TATAA Biocenter AB, Göteborg, Sweden). Primers sequences are listed in Supplementary Table S4.

Western blotting. Cells were lysed with RIPA buffer in the presence of proteases and phosphatase inhibitor mixture. Forty microgram of total proteins was separated by 8-10\% Tris Glycine SDS-PAGE (Invitrogen) and transferred to a polyvinylidene difluoride membrane (Hybond-P, Amersham, Buckinghamshire, UK). Membranes were blocked in Tris-buffered saline with $2 \% \mathrm{BSA}$ and $0.2 \%$ Tween 20 and incubated overnight at $4{ }^{\circ} \mathrm{C}$ with primary antibodies listed in Supplementary Table S1. Immunoreactive bands were detected with peroxidaseconjugated secondary antibodies listed in Supplementary Table S2 and with ECL Plus detection system (Amersham).

Statistics. Values are presented as mean \pm S.D. Statistical significance was calculated by using Student's $t$-test, $P<0.05$ was considered significantly different.

\section{Conflict of Interest}

The authors declare no conflict of interest.

Acknowledgements. We thank Virginia Rubio-López for the technical assistance. Dr Chacón Fernández PJ generously provided mouse E17 FVB embryos and Wistar adult rats. The authors are supported by the Fundación Progreso y Salud, Consejería de Salud, Junta de Andalucía (Grant PI-0022/2008); FEDER co-funded grants from Consejería de Innovación Ciencia y Empresa, Junta de Andalucía (Grant CTS-6505; INP-2011-1615-900000); FEDER co-funded grants from Instituto de Salud Carlos III (Red TerCel-Grant RD12/0019/0028; PI10/00964 and PI10/00871) and the Ministry of Health and Consumer Affairs (Advanced Therapies Program Grant TRA-120). Support from FSED and FAID allow access to databanks. CIBERDEM is an initiative of the Instituto de Salud Carlos III.

1. Brenes RA, Bear M, Jadlowiec C, Goodwin M, Hashim P, Protack CD et al. Cell-based interventions for therapeutic angiogenesis: review of potential cell sources. Vascular 2012; 20: $360-368$

2. Raval Z, Losordo DW. Cell therapy of peripheral arterial disease: from experimental findings to clinical trials. Circ Res 2013; 112: 1288-1302.

3. Silvestre JS. Pro-angiogenic cell-based therapy for the treatment of ischemic cardiovascular diseases. Thromb Res 2012; 130(Suppl 1): S90-S94.

4. Ruiz-Salmeron R, de la Cuesta-Diaz A, Constantino-Bermejo M, Perez-Camacho I, Marcos-Sanchez F, Hmadcha A et al. Angiographic demonstration of neoangiogenesis after intra-arterial infusion of autologous bone marrow mononuclear cells in diabetic patients with critical limb ischemia. Cell Transplantat 2011; 20: 1629-1639.

5. Moretti A, Bellin M, Jung CB, Thies TM, Takashima Y, Bernshausen A et al. Mouse and human induced pluripotent stem cells as a source for multipotent isl1 + cardiovascular progenitors. FASEB J 2010; 24: 700-711.

6. Moretti A, Caron L, Nakano A, Lam JT, Bernshausen A, Chen Y et al. Multipotent embryonic is $1+$ progenitor cells lead to cardiac, smooth muscle, and endothelial cell diversification. Cell 2006; 127: 1151-1165.

7. Hmadcha A, Dominguez-Bendala J, Wakeman J, Arredouani M, Soria B. The immune boundaries for stem cell based therapies: problems and prospective solutions. $J$ Cell Mol Med 2009; 13: 1464-1475.

8. Ben-David U, Benvenisty N. The tumorigenicity of human embryonic and induced pluripotent stem cells. Nat Rev Cancer 2011; 11: 268-277.

9. Lalu MM, McIntyre L, Pugliese C, Fergusson D, Winston BW, Marshall JC et al. Safety of cell therapy with mesenchymal stromal cells (safecell): a systematic review and metaanalysis of clinical trials. PLoS One 2012; 7: e47559.

10. Patel P, West-Mays J, Kolb M, Rodrigues JC, Hoff CM, Margetts PJ. Platelet derived growth factor $b$ and epithelial mesenchymal transition of peritoneal mesothelial cells. Matrix Biol 2010; 29: 97-106.

11. Galvez P, Clares B, Hmadcha A, Ruiz A, Soria B. Development of a cell-based medicinal product: regulatory structures in the european union. Br Med Bull 2013; 105: 85-105.

12. Crisan M, Chen CW, Corselli M, Andriolo G, Lazzari L, Peault B. Perivascular multipotent progenitor cells in human organs. Ann N Y Acad Sci 2009; 1176: 118-123.

13. Crisan M, Yap S, Casteilla L, Chen CW, Corselli M, Park TS et al. A perivascular origin for mesenchymal stem cells in multiple human organs. Cell Stem Cell 2008; 3: 301-313.

14. Siegel G, Schafer R, Dazzi F. The immunosuppressive properties of mesenchymal stem cells. Transplantation 2009; 87: S45-S49. 
15. Pelacho B, Mazo M, Gavira JJ, Prosper F. Adult stem cells: from new cell sources to changes in methodology. J Cardiovasc Transl Res 2011; 4: 154-160.

16. van Tuyn J, Atsma DE, Winter EM, van der Velde-van Dijke I, Pijnappels DA, Bax NA et al. Epicardial cells of human adults can undergo an epithelial-to-mesenchymal transition and obtain characteristics of smooth muscle cells in vitro. Stem Cells 2007; 25: 271-278.

17. Kawaguchi M, Bader DM, Wilm B. Serosal mesothelium retains vasculogenic potential. Dev Dyn 2007; 236: 2973-2979.

18. Lachaud CC, Pezzolla D, Dominguez-Rodriguez A, Smani T, Soria B, Hmadcha A Functional vascular smooth muscle-like cells derived from adult mouse uterine mesothelial cells. PLoS One 2013; 8: e55181.

19. Rinkevich Y, Mori T, Sahoo D, Xu PX, Bermingham Jr JR, Weissman IL. Identification and prospective isolation of a mesothelial precursor lineage giving rise to smooth muscle cells and fibroblasts for mammalian internal organs, and their vasculature. Nat Cell Biol 2012 14: $1251-1260$

20. Li Y, Wang J, Asahina K. Mesothelial cells give rise to hepatic stellate cells and myofibroblasts via mesothelial-mesenchymal transition in liver injury. Proc Natl Acad Sci USA 2013; 110: 2324-2329.

21. Chau YY, Bandiera R, Serrels A, Martínez-Estrada OM, Qing W, Lee M et al. Visceral and subcutaneous fat have different origins and evidence supports a mesothelial source. Nat Cell Biol 2014; 16: 367-375.

22. Wada AM, Smith TK, Osler ME, Reese DE, Bader DM. Epicardial/mesothelial cell line retains vasculogenic potential of embryonic epicardium. Circ Res 2003; 92: 525-531.

23. Liu Q, Mao H, Nie J, Chen W, Yang Q, Dong X et al. Transforming growth factor \{beta\}1 induces epithelial-mesenchymal transition by activating the jnk-smad3 pathway in rat peritoneal mesothelial cells. Perit Dial Int 2008; 28(Suppl 3): S88-S95.

24. Nasreen N, Mohammed KA, Mubarak KK, Baz MA, Akindipe OA, Fernandez-Bussy S et al. Pleural mesothelial cell transformation into myofibroblasts and haptotactic migration in response to tgf-beta1 in vitro. Am J Physiol Lung Cell Mol Physiol 2009; 297 L115-L124.

25. Asahina K, Zhou B, Pu WT, Tsukamoto H. Septum transversum-derived mesothelium gives rise to hepatic stellate cells and perivascular mesenchymal cells in developing mouse liver. Hepatology 2011; 53: 983-995.

26. Mikawa T, Gourdie RG. Pericardial mesoderm generates a population of coronary smooth muscle cells migrating into the heart along with ingrowth of the epicardial organ. Dev Biol 1996; 174: 221-232.

27. Que J, Wilm B, Hasegawa H, Wang F, Bader D, Hogan BL. Mesothelium contributes to vascular smooth muscle and mesenchyme during lung development. Proc Natl Acad Sci USA 2008; 105: 16626-16630.

28. Wilm B, Ipenberg A, Hastie ND, Burch JB, Bader DM. The serosal mesothelium is a majo source of smooth muscle cells of the gut vasculature Development 2005: 132. 5317-5328.

29. Zhou B, Ma Q, Rajagopal S, Wu SM, Domian I, Rivera-Feliciano J et al. Epicardia progenitors contribute to the cardiomyocyte lineage in the developing heart. Nature 2008; 454: 109-113.

30. Cai CL, Martin JC, Sun Y, Cui L, Wang L, Ouyang K et al. A myocardial lineage derives from tbx18 epicardial cells. Nature 2008; 454: 104-108.

31. Lee MJ, Wu Y, Fried SK. Adipose tissue heterogeneity: implication of depot differences in adipose tissue for obesity complications. Mol Aspects Med 2013; 34: 1-11.

32. Christiaens V, Lijnen HR. Angiogenesis and development of adipose tissue. $\mathrm{Mol} \mathrm{Cell}$ Endocrinol 2010; 318: 2-9.
33. Nishimura S, Manabe I, Nagasaki M, Hosoya Y, Yamashita H, Fujita H et al. Adipogenesis in obesity requires close interplay between differentiating adipocytes, stromal cells, and blood vessels. Diabetes 2007; 56: 1517-1526.

34. Lv ZD, Na D, Ma XY, Zhao C, Zhao WJ, Xu HM. Human peritoneal mesothelial cell transformation into myofibroblasts in response to tgf-ss1 in vitro. Int J Mol Med 2011; 27: 187-193

35. Jain M, He Q, Lee WS, Kashiki S, Foster LC, Tsai JC et al. Role of cd44 in the reaction of vascular smooth muscle cells to arterial wall injury. J Clin Invest 1996; 98: 877

36. Masaki T. Historical review: endothelin. Trends Pharmacol Sci 2004; 25: 219-224.

37. Ha H, Yu MR, Lee HB. High glucose-induced pkc activation mediates tgf-beta 1 and fibronectin synthesis by peritoneal mesothelial cells. Kidney Int 2001; 59: 463-470.

38. Kang DH, Hong YS, Lim HJ, Choi JH, Han DS, Yoon KI. High glucose solution and spent dialysate stimulate the synthesis of transforming growth factor-beta1 of human peritoneal mesothelial cells: effect of cytokine costimulation. Perit Dial Int 1999; 19: 221-230.

39. Ahmed N, Maines-Bandiera S, Quinn MA, Unger WG, Dedhar S, Auersperg N. Molecular pathways regulating egf-induced epithelio-mesenchymal transition in human ovarian surface epithelium. Am J Physiol Cell Physiol 2006; 290: C1532-C1542.

40. Stylianou E, Jenner LA, Davies M, Coles GA, Williams JD. Isolation, culture and characterization of human peritoneal mesothelial cells. Kidney Int 1990; 37: 1563-1570.

41. Kattman SJ, Huber TL, Keller GM. Multipotent flk-1 + cardiovascular progenitor cells give rise to the cardiomyocyte, endothelial, and vascular smooth muscle lineages. Dev Cell 2006; 11: 723-732.

42. Bu L, Jiang X, Martin-Puig S, Caron L, Zhu S, Shao Y et al. Human isl1 heart progenitors generate diverse multipotent cardiovascular cell lineages. Nature 2009; 460: 113-117.

43. Oikawa H, Hayashi K, Maesawa C, Masuda T, Sobue K. Expression profiles of nestin in vascular smooth muscle cells in vivo and in vitro. Exp Cell Res 2010; 316: 940-950.

44. Tamama K, Fan VH, Griffith LG, Blair HC, Wells A. Epidermal growth factor as a candidate for ex vivo expansion of bone marrow-derived mesenchymal stem cells. Stem Cells 2006 ; 24: $686-695$

45. Jang YH, Shin HS, Sun Choi H, Ryu ES, Jin Kim M, Ki Min S et al. Effects of dexamethasone on the tgf-beta1-induced epithelial-to-mesenchymal transition in human peritoneal mesothelial cells. Lab Invest 2013; 93: 194-206.

46. Ksiazek K, Korybalska K, Jorres A, Witowski J. Accelerated senescence of human peritoneal mesothelial cells exposed to high glucose: the role of tgf-beta1. Lab Invest 2007; 87: $345-356$.

(c) ()ㅇ Cell Death and Disease is an open-access journal BY NC No published by Nature Publishing Group. This work is licensed under a Creative Commons Attribution-NonCommercialNoDerivs 3.0 Unported License. The images or other third party material in this article are included in the article's Creative Commons license, unless indicated otherwise in the credit line; if the material is not included under the Creative Commons license, users will need to obtain permission from the license holder to reproduce the material. To view a copy of this license, visit http://creativecommons.org/ licenses/by-nc-nd/3.0/

Supplementary Information accompanies this paper on Cell Death and Disease website (http://www.nature.com/cddis) 